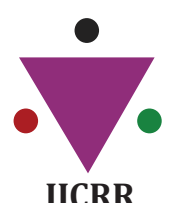

Section: Healthcare Sci. Journal Impact Factor: $6.1(2018)$ ICV: 90.90 (2018)

\title{
Port Site Incisional Hernia Incidence in Laparoscopic Cholecystectomy Following Non-Fascial Sheath Closure: Experience from a Busy Centre
}

\author{
Abdul Maajed Jehangeer ${ }^{1}$, Rohi Wani' ${ }^{2}$, Wasim Lone ${ }^{3}$, Syed Aga Nadeem ${ }^{4}$ \\ 'MB, MS (Gen Surg) FACS, Consultant Surgeon, Government Gousia Hospital, Srinagar; ${ }^{2}$ MD (Path), Associate Professor, Department \\ of Pathology, Government Medical College, Srinagar; ${ }^{3} \mathrm{MB}$, MS (Gen Surg). Surgeon Specialist, Government Gousia Hospital, Srinagar; \\ ${ }^{4} \mathrm{MB}$, MS (Gen Surg). Surgeon Specialist, Government Gousia Hospital, Srinagar..
}

\section{ABSTRACT}

Aim: To study the incidence of post-operative port site hernias in patients undergoing laparoscopic cholecystectomy in our centre.

Methodology: This study was carried out on patients undergoing laparoscopic cholecystectomy with non-closure of port-site fascial sheath who attended for follow-up in our outpatient clinic up to one year from the date of surgery.

Results: None of the patients in our study came up with any indication of port site hernia.

Conclusion: Port-site closure of fascial sheath $\leq 10 \mathrm{~mm}$ may not be necessary in laparoscopic cholecystectomy to prevent portsite incisional hernias.

Key Words: Laparoscopy, Port site, Hernia, Trocar

\section{INTRODUCTION}

Laparoscopic cholecystectomy is one of the most frequently performed procedures in our centre.

The greatest advantages of laparoscopy when compared to open surgery include the faster recovery times, shorter hospital stays, decreased post-operative pain, earlier return to work and resumption of normal daily activity as well as cosmetic benefits ${ }^{1}$.

Larger port size and increasing the number of ports needed to perform more complex laparoscopic procedures is likely to increase the incidence of port site hernias. These hernias tend to develop more frequently at umbilical and midline port sites due to the thinness of the umbilical skin and weakness in the linea alba ${ }^{2}$.

Incisional hernia is a rare complication that can also occur after laparoscopic surgeries. The incidence of port site hernia after laparoscopic surgery lies between $0.38 \%$ to $5.4 \%$ with overall incidence of $1.7^{3}$.

Port site hernia can cause a whole range of presentations ranging from being asymptomatic to serious complication like strangulated bowel hernia. The interval between operation and diagnosis of port site hernia varies between studies and depends on follow-up regimes. Where data are available, time to diagnosis ranged from 5 days to 3 years with an average of 9.2 months ${ }^{4}$.

Bowel involvement can present as bowel incarceration, bowel obstruction or bowel evisceration. Again, these presentations can occur as early as within 2 days of surgery to weeks after surgery ${ }^{5}$.

\section{MATERIAL AND METHODS}

This is a prospective study of 324 patients, all of whom underwent laparoscopic cholecystectomy in our department

\section{Corresponding Author:}

Dr. Abdul Maajed Jehangeer, MB, MS (Gen Surg), FACS, Consultant and Head of the Unit, Department of Surgery, Government Gousia Hospital, Khanyar-Srinagar, Jammu \& Kashmir.190003; Cell No: 9906567537, 7889924181; Email: maajed@gmail.com

ISSN: 2231-2196 (Print)

Received: 13.10 .2019
ISSN: $0975-5241$ (Online)

Revised: 30.10 .2019
Accepted: 16.11 .2019 
from $1^{\text {st }}$ September 2017 till $31^{\text {st }}$ August 2018. Patients with past history of lower segment caesarean section (LSCS- both lower mid-line and pfannenstiel incisions), hypertensive and/ or hypothyroid patients and elderly upto 70 years of age were included. Patients with mild to moderate chronic obstructive pulmonary disease (COPD) and children between 8-12 years of age were also included.

Patients with diabetes, those with previous upper mid-line or upper paramedian incisions and obese patients were excluded.

In our series, at the time of laparoscopic cholecystectomy, umbilical port for camera was inserted by $10 \mathrm{~mm}$ trocar both by the open and closed technique. We used two $10 \mathrm{~mm}$ ports for the umbilical and epigastric region. The remaining two lateral ports were $5 \mathrm{~mm}$ each.

In all our patients, fascia was not closed, and only subcuticular suturing was done in all ports. A suction drain was used in all patients during procedure and was removed on post op day 1 before the patient was discharged.

All relevant data were collected in a proforma mentioning age, sex, associated co-morbidities, ASA score, per operative and postoperative complications and pain measurement through numeric rating scale.

Patients were followed up in our clinic for regular antiseptic dressings on alternate days following surgery till sutures were removed, usually on the $9^{\text {th }}$ or $10^{\text {th }}$ post-operative day. Afterwards, all patients were followed up one month after surgery and then after three months and six months. Finally, all patients were asked to appear for follow-up consultation one-year post surgery.

\section{RESULTS}

All patients in our series underwent laparoscopic cholecystectomy.

Out of a total of 324 patients 249 were female $(77 \%)$ and 75 were male (23\%). 146 patients had co-morbidities like hypertension, hypothyroidism and COPD (45\%). All of them were ASA I or ASA II. There were four children between the ages of 8-12 years in our study (Table 1).

Table 1. Distribution of patients according to sex, comorbidities and the duration of follow-up

\begin{tabular}{lc}
\hline Total number of patients & 324 \\
Females & 249 \\
Males & 75 \\
Children & 4
\end{tabular}

Number of patients attending follow-up at 1 month

Number of patients attending follow-up at 3 months

Number of patients attending follow-up at 6 months

Number of patients attending follow-up at 12 months

Patients with co-morbidities

292

Number of patients with clinical evidence of port site hernia

Per/post-operative complications were the following:

a) Three cases were converted to open cholecystectomy due to difficult dissection. Out of these, one patient needed blood transfusion due to injury to the middle hepatic vein during surgery. One patient needed external biliary drainage by T-tube placement.

b) One patient needed epigastric port site fascial extension for retrieval of a difficult gallbladder. Her fascial sheath was closed by 20 vicryl.

c) Two patients had subcutaneous bruising following open port placement which subsided before suture removal.

d) One patient had prolonged bile leak which subsided three weeks following surgery.

e) Four patients had port site hypertrophic scars appreciable between 3-6 months post-surgery.

f) One patient had prolonged epigastric port site infection which lasted for 3 weeks but resolved with oral antibiotics.

After suture removal, follow-up was at one-month postsurgery in which 292 patients attended (90\%). The second follow-up was scheduled three months post-surgery and 266 patients complied (82\%). The third follow-up was at six months post-procedure and 201 patients attended (62\%). Finally, 165 patients came to our final follow-up scheduled one-year post surgery (51\%).

We found no incidence of positive cough impulse or herniation in all our patients who attended clinic for follow-up upto a period of one-year post procedure.

\section{DISCUSSION}

Laparoscopic cholecystectomy has become the "gold standard" for surgical management of uncomplicated gallstone disease as it offers a myriad of advantages resulting in rapid post-operative recovery. However, the adoption of this technique has resulted in the emergence of new, specific operative complications. The occurrence of an incisional hernia at the site of entry of a port is a serious complication in laparoscopy because most port site hernias require further surgery ${ }^{6}$. 
Our study shows that $10 \mathrm{~mm}$ ports created for laparoscopic cholecystectomy without closure of the fascial sheath are not at risk for port site hernia formation up-to a period of oneyearpost surgery. More studies will be needed to look for this complication beyond the post-procedure period of one year.

Coda et $\mathrm{al}^{4}$ noted that the onset of port site hernia occurs later rather than immediately after surgery and might elude a surgeon in many surveys unless an extended follow-up procedure has been established. As such, there is possibility of under reporting in the literature especially for studies reporting on non-fascial sheath closure in ports up to $10 \mathrm{~mm}$ diameter.

Data from literature encourages fascial closure of ports $>10$ $\mathrm{mm}$ for other surgeries like laparoscopic colon-rectal and bariatric procedures or for those laparoscopic cholecystectomy patients in whom port-sites have been extended for retrieval of a difficult gallbladder. It points towards fascial closure in all such cases as incidence of port site hernia increases with the size of the $\operatorname{trocar}^{3,7}$ although there are other risk factors involved like wound infection, diabetes mellitus, obesity, connective tissue disorders operating times, port-site manipulations among others.

Some authors like Duron et $\mathrm{al}^{8}$ have doubted that any effects of fascial closure are related to a trocar site hernia. They commented that although it has been stated that fascia closure of trocar holes, which is sometimes difficult, might preclude or decrease the incidence of obstructions, his study as well as that by Tonouchi et $\mathrm{al}^{9}$ has reported that adhesions or incarcerations, whether median or lateral can still occur after a fascial closure.

Similarly, Liu and McFadden ${ }^{10}$ conclude that the use of nonbladed laparoscopic trocars preclude the need for fascia closure even in ports up to $12 \mathrm{~mm}$ in diameter. Singal et $\mathrm{al}^{2} \mathrm{ar}-$ rive at a similar conclusion and state that non-obese patients undergoing their first laparoscopic surgery with $10 \mathrm{~mm}$ port created by trocar may not need fascia closure. However, not closing the fascial defect is thought to be implicated in port site hernia formation by many authors ${ }^{6,9,11}$ although closing the fascia is certainly not preventive. This is demonstrated by the fact that in some studies, hernias were identified despite fascial closure in all cases c $^{8,9,11,12}$.

\section{CONCLUSION}

Port site hernia is a rare complication of laparoscopic surgery but assumes significance due to the associated morbidity and need for a revision procedure which may preclude benefits offered by the primary procedure. While there is consensus in the literature about closure of fascia in larger, $12 \mathrm{~mm}$ ports there is, however conflict about fascial closure in lesser $\leq 10$ $\mathrm{mm}$ ports with some authors deeming it unnecessary while others advocating proper fascial closure before subcuticular suturing. Our prospective study has followed up patients who have had no fascial closure of any of their port sites. Also, after reviewing literature we note that this condition may be overlooked due to the short follow-up of patients after surgery, as such we carried out this study for a longer, one-year post-operative time period.

In conclusion, we acknowledge that even though there is conflict in literature regarding fascial closure of $\leq 10 \mathrm{~mm}$ ports however, our data suggests that patients with our selection criteria undergoing laparoscopic cholecystectomy with $\leq 10 \mathrm{~mm}$ ports may not need fascial closure.

\section{ACKNOWLEDGEMENT}

Authors acknowledge the immense help received from the scholars whose articles are cited and included in references of this manuscript. The authors are also grateful to authors / editors /publishers of all those articles, journals and books from where the literature for this article has been reviewed and discussed.

\section{Source of Funding: Nil.}

\section{Conflict of interest: Nil.}

Informed consent: The corresponding author can confirm that informed consent was obtained from every patient prior to procedure and the benefits and risks of the procedure were explained prior to surgery by the operating surgeon.

\section{REFERENCES}

1. Mandrioli M, Inaba K, Piccinni A, Biscardi A, Sartelli M, Agresta F, et al. World J Gastroenterol. 2016 Jan 14; 22(2): 668-680.

2. Singal R, Zaman M, Mittal A, Singal S, Sandhu K, Mittal A. No need of fascia closure to reduce trocar site hernia rate in laparoscopic surgery: A prospective study of 200 non-obese patients. Gastroenterology Res. 2016 Oct; 9 (4-5): 70-73.

3. Bunting DM. Port-site hernia following laparoscopic cholecystectomy. JSLS. 2010 Oct-Dec; 14 (4): 490-7.

4. Coda A, Bossotti M, Ferri F, Mattio R, Ramellini G, Poma A, et al. Incisional hernia and fascial defect following laparoscopic surgery. Surg Laparosc Endosc Percutan Tech. 2000 Feb; 10(1): $34-8$.

5. Sharma R, Mehta D, Goyal M, Gupta S. The earliest presenting umbilical port site hernia following laparoscopic cholecystectomy: A case report. J Clin Diagn Res. 2016 Jul; 10(7): PD18PD19.

6. Callery MP, Strasberg SM, Soper NJ. Complications of laparoscopic general surgery. Gastrointest Endosc Clin N Am 1996 Apr; 6(2):423-444.

7. Kadar N,Reich H, Liu CY, Manko GF, Gimpelson R. Incisional hernias after major gynaecologic procedures. AMJ Obstet Gynecol 1993 May; 168(5):1493-1495.

8. Duron JJ, Hay JM, Msika S, Gaschard D, et al. Prevalence and mechanisms of small intestinal obstruction following laparoscopic abdominal surgery: a retrospective multicenter study. Arch Surg 2000 Feb; 135(2):208-212. 
9. Tonouchi H, Ohmori Y, Kobayashi M, Kusunoki M. Trocar site hernia. Arch Surg. 2004 Nov; 139(11): 1248-1256.

10. Liu CD, McFadden DW. Laparoscopic port sites do not require fascial closure when nonbladed trocars are used. Am Surg. 2000 Sep; 66(9): 853-854.

11. Nassar AH, Ashkar KA, Rashed AA, Abdulmoneum MG. Laparoscopic cholecystectomy and the umbilicus. Br J Surg. 1997 May; 84(5): 630-633.
12. Azurin DJ, Go LS, Arroyo LR, Kirkland ML. Trocar site herniation following laparoscopic cholecystectomy and the significance of an incidental preexisting umbilical hernia. Am Surg 1995 Aug; 61 (8):718-20. 